\title{
Marked attenuation of the amplitude of transcranial motor-evoked potentials after intravenous bolus administration of ketamine: a case report
}

\author{
Kenta Furutani ${ }^{1,2^{*}}$, Mari Matsuhashi ${ }^{2}$, Hiroyuki Deguchi ${ }^{2}$, Yusuke Mitsuma ${ }^{2}$, Nobuko Ohashi ${ }^{2}$ and Hiroshi Baba ${ }^{2}$
}

\begin{abstract}
Background: It is believed that ketamine does not affect motor-evoked potential amplitude, whereas various anesthetic drugs attenuate the amplitude of transcranial motor-evoked potential. However, we encountered a patient with marked attenuation of motor-evoked potential amplitude after intravenous bolus administration of ketamine.

Case presentation: A 15-year-old Japanese girl with a diagnosis of adolescent idiopathic scoliosis was admitted to our hospital to undergo posterior spinal fusion at T4-L3. After induction of general anesthesia using a continuous infusion of propofol and remifentanil, we confirmed that transcranial electrical motor-evoked potentials were being recorded correctly. Ketamine $1.25 \mathrm{mg} / \mathrm{kg}$ was administered intravenously for intraoperative and postoperative analgesia. About 3 minutes later, the motor-evoked potential amplitude was markedly attenuated. No other drugs were administered except for ketamine. The patient's vital signs were stable, and the surgery had not yet started. The motor-evoked potential amplitude was recovered at about 6 minutes after administration of ketamine. The surgery was performed uneventfully, and the patient had no neurologic deficit when she emerged from general anesthesia.
\end{abstract}

Conclusions: Although there is a widely held belief in the field of anesthesiology that ketamine does not affect motorevoked potential amplitude, it has been suggested that ketamine could affect its monitoring.

Keywords: Bolus administration, Ketamine, Monitoring, Motor-evoked potentials, Spine surgery

\section{Background}

Various anesthetic drugs, including volatile anesthetic agents, propofol, and midazolam, attenuate the amplitude of transcranial motor-evoked potentials (MEPs) [1, 2]. It is believed that ketamine does not affect the MEP amplitude [3]. Further, ketamine has an analgesic effect as well as a hypnotic effect. Continuous infusion of ketamine combined with opioids is known to attenuate postoperative pain after complex spine surgery [4], which is considered to be a particularly painful procedure [5]. Therefore, ketamine is a useful drug in complex spine surgery for both recording MEPs and improving the quality of postoperative analgesia.

\footnotetext{
* Correspondence: kenta-f@med.niigata-u.ac.jp

1 Department of Anesthesiology, Uonuma Institute of Community Medicine, Niigata University Medical and Dental Hospital, 4132 Urasa, Minami-Uonuma, Niigata 949-7302, Japan

${ }^{2}$ Department of Anesthesiology, Niigata University Medical and Dental Sciences, 1-757 Asahimachi-Dori, Chuo-ku, Niigata 951-8510, Japan
}

However, although there are no reports of ketamine reducing the amplitude of MEPs, we encountered a case of marked attenuation of the MEP amplitude after intravenous bolus administration of ketamine before posterior spinal fusion in a patient with adolescent idiopathic scoliosis.

\section{Case presentation}

A 15-year-old Japanese girl with a diagnosis of adolescent idiopathic scoliosis was admitted to our hospital to undergo posterior spinal fusion at T4-L3. She was a high school student and did not present any symptoms at admission. She did not take any medications prior to the surgery. Her past medical, social, environmental, and family history was not appreciable. She was $147 \mathrm{~cm}$ tall, and her weight was $40 \mathrm{~kg}$. She had a Cobb angle of 60 degrees. She had no neurological symptoms. Her temperature was $36.8^{\circ} \mathrm{C}$, her blood pressure was $118 / 64 \mathrm{mmHg}$, and her

(c) The Author(s). 2018 Open Access This article is distributed under the terms of the Creative Commons Attribution 4.0 International License (http://creativecommons.org/licenses/by/4.0/), which permits unrestricted use, distribution, and 
pulse was 92 beats per minute. Laboratory findings at admission were as follows. Her white blood cell count was $6860 / \mu \mathrm{l}$, red blood cell count $472 \times 10^{4} / \mu \mathrm{l}$, hemoglobin $14.3 \mathrm{~g} / \mathrm{dl}$, hematocrit $42.1 \%$, platelets $30.8 \times 10^{4} / \mu \mathrm{l}$, aspartate transaminase $19 \mathrm{IU} / \mathrm{L}$, alanine transaminase $15 \mathrm{IU} / \mathrm{L}$, total bilirubin $0.5 \mathrm{mg} / \mathrm{dl}, \gamma$-glutamyl transferase $16 \mathrm{IU} / \mathrm{L}$, alkaline phosphatase $371 \mathrm{IU} / \mathrm{L}$, total protein $8.2 \mathrm{~g} / \mathrm{dl}$, albumin $5.2 \mathrm{~g} / \mathrm{dl}$, blood urea nitrogen $11 \mathrm{mg} / \mathrm{dl}$, creatinine $0.39 \mathrm{mg} / \mathrm{dl}$, sodium $141 \mathrm{mEq} / \mathrm{L}$, potassium $4.5 \mathrm{mEq} / \mathrm{L}$, chloride $102 \mathrm{mEq} / \mathrm{L}$, C-reactive protein $0.01 \mathrm{mg} / \mathrm{dl}$, urinalysis $\mathrm{pH} 6.0$, no uric protein, no urinary sugar, no ketone body, and no uric blood. No microbial examination was performed.

We planned general anesthesia using a target-controlled infusion of propofol and a continuous infusion of remifentanil to record MEPs and somatosensory evoked potentials (SSEPs). In addition, we planned to use both bolus and continuous infusions of ketamine, followed by intravenous patient-controlled fentanyl as postoperative analgesia because we believed that ketamine did not affect MEP monitoring.

After securing an intravenous line in the patient's forearm, general anesthesia was induced using a target-controlled infusion of propofol $4 \mu \mathrm{g} / \mathrm{ml}$ and remifentanil $0.3 \mu \mathrm{g} / \mathrm{kg} / \mathrm{minute}$. After administration of rocuronium $20 \mathrm{mg}$, the trachea was intubated using a reinforced endotracheal tube. Thereafter, $1 \mathrm{~g}$ of cefazolin sodium was administered intravenously every 3 hours during the surgery and every 12 hours until postoperative day 1 .

We started preparation for recording the MEPs and SSEPs. MEPs were evoked by transcranial electrical stimulation (a train of five pulses with an interstimulus interval of 2 milliseconds; supramaximal stimulus, $400 \mathrm{~V}$ ) with screw electrodes fixed at $2 \mathrm{~cm}$ anterior to C3 and C4 (cathode and anode, respectively, following the international 10-20 system). MEPs and SSEPs were recorded using an intraoperative neurophysiologic monitoring system (Neuromaster MEE-1216; Nihon Kohden, Tokyo, Japan). MEPs were recorded bilaterally from the abductor pollicis, quadriceps femoris, tibialis anterior, and flexor hallucis brevis muscles. SSEPs were evoked by stimulation $(30 \mathrm{~mA})$ of the sciatic nerve and recorded from $2 \mathrm{~cm}$ posterior to $\mathrm{Cz}$ (averaging the signals generated by 200 stimulations).

After the patient was turned to a prone position, we confirmed that we could record MEPs from all targeted muscles without difficulty. We maintained general anesthesia using a target-controlled infusion of propofol $3.3 \mu \mathrm{g} / \mathrm{ml}$ and remifentanil $0.2 \mu \mathrm{g} / \mathrm{kg} /$ minute. The patient's bispectral index values were below 60 , and her vital signs were stable. Several minutes before the skin incision was made, the attending anesthesiologist evaluating the MEPs discovered that they were markedly attenuated (Fig. 1). The attending anesthesiologist had not changed the propofol infusion rate and had not administered any other drugs except for

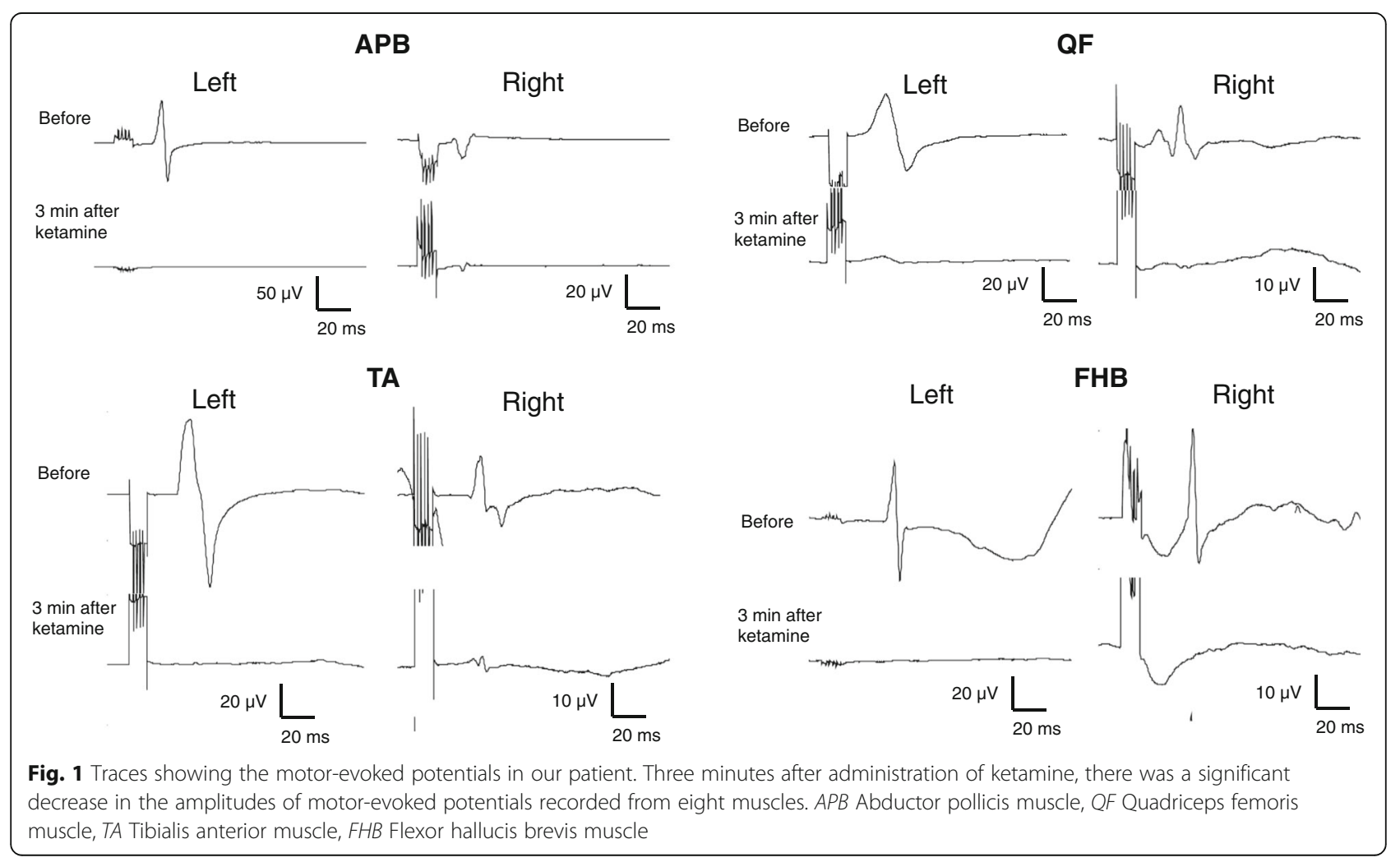


intravenous bolus administration of ketamine $50 \mathrm{mg}$ $(1.25 \mathrm{mg} / \mathrm{kg})$. Ketamine was administered about 3 minutes before the change in MEP waveforms. The patient's blood pressure, heart rate, peripheral oxygen saturation, end-tidal $\mathrm{CO}_{2}$, and body temperature remained stable. The surgery had not started at that time. About 6 minutes after administration of ketamine, the MEP amplitudes were recovered.

The surgery was performed uneventfully, and the patient had no neurologic deficit when she emerged from general anesthesia. Intravenous patient-controlled analgesia (a combination of fentanyl $25 \mu \mathrm{g} / \mathrm{ml}$ and ketamine $2.5 \mathrm{mg} / \mathrm{ml}$, background infusion $1 \mathrm{ml} /$ hour, bolus $1 \mathrm{ml}$, and lockout time 10 minutes) was used for postoperative pain management. The patient was discharged on postoperative day 11 without any complications. She was well without complications at 2 years after the surgery.

\section{Discussion}

This case report highlights the marked attenuation of amplitude of transcranial MEPs after an intravenous bolus administration of ketamine. It is widely believed that ketamine does not affect MEP amplitude [3]. However, in our patient, the amplitude was significantly decreased $3 \mathrm{mi}-$ nutes after administration of ketamine $1.25 \mathrm{mg} / \mathrm{kg}$. Our experience with this patient suggests that ketamine may indeed affect the MEP amplitude, so anesthesiologists need to be cautious when considering the timing and dose of intravenous administration of ketamine.

Anesthesiologists believe that ketamine does not affect MEP amplitude. Indeed, bolus administration of ketamine $0.5 \mathrm{mg} / \mathrm{kg}$ during either propofol/remifentanil or $\mathrm{N}_{2} \mathrm{O}$ /sufentanil anesthesia has been reported to have no significant influence on the amplitude of MEPs evoked by transcranial electrical stimulation $[6,7]$.

However, in our patient, it is possible that bolus administration of ketamine $1.25 \mathrm{mg} / \mathrm{kg}$ decreased the amplitude of her MEPs. Bolus administration of ketamine was reported to decrease MEP amplitude in a rabbit model [8]. In another study performed in rabbits, continuous infusion of $S(+)$-ketamine decreased the MEP amplitude in a dose-dependent manner without affecting spinal cord evoked potentials [9]. These findings suggest that ketamine may inhibit the activity of spinal motoneurons. Although Kalkman et al. [3] concluded that ketamine $1 \mathrm{mg} / \mathrm{kg}$ did not affect MEP amplitude in humans, it was suspected that the amplitude was reduced by administration of ketamine to approximately $50 \%$ of control values in two of five study participants. In our patient, although we used a clinically appropriate $1.25 \mathrm{mg} / \mathrm{kg}$ dose of ketamine 3 minutes before MEP recordings were started, the waveforms of the MEPs disappeared almost completely. No drugs were administered in addition to ketamine in this patient, and the surgery had not yet started. In addition, her vital signs were stable. Therefore, we hypothesized that a higher effect site concentration of ketamine, which was achieved by bolus intravenous administration, might have affected the MEP amplitude.

Subanesthetic doses of ketamine may improve the quality of postoperative analgesia. Intraoperative and postoperative administration of low-dose ketamine reduced cumulative morphine consumption in patients who had undergone posterior spinal fusion for adolescent idiopathic scoliosis [4]. In a recent meta-analysis, administration of ketamine was reported to decrease both cumulative morphine consumption and the incidence of postoperative nausea and vomiting [10]. At our hospital, anesthesiologists have used ketamine for intraoperative and postoperative analgesia during complex spine surgeries, because these procedures are particularly painful [5] and because it is believed that ketamine does not affect MEP monitoring. If ketamine does affect the MEP amplitude, especially in complex spine surgery where intraoperative neurophysiologic monitoring is required, bolus administration of ketamine would interfere with monitoring. If our hypothesis is true, the anesthesiologist should adjust the timing of administration of ketamine so that the surgeon can appropriately modify the surgical procedure according to the correct results of MEP monitoring. A prospective, randomized clinical trial is needed to confirm whether ketamine truly affects the MEP amplitude.

\section{Conclusions}

This report describes a patient in whom the MEP amplitude was markedly attenuated after intravenous bolus injection of ketamine $1.25 \mathrm{mg} / \mathrm{kg}$. This case suggests that the timing of ketamine administration should be considered carefully, especially when the surgeon is performing a procedure that requires close attention to the results of neurophysiologic monitoring.

\section{Abbreviations \\ MEP: Transcranial motor-evoked potential; SSEP: Somatosensory evoked potential}

\section{Acknowledgements}

We thank Editage (www.editage.jp) for English language editing.

\section{Funding}

The authors did not receive any specific grant from funding agencies in the public, commercial, or not-for-profit sectors for this report.

\section{Availability of data materials}

Data sharing not applicable to this article, because no datasets were generated or analyzed during the current study.

\section{Authors' contributions}

$\mathrm{KF}$ and $\mathrm{NO}$ were the patient's attending anesthesiologists and performed the data collection. KF and MM drafted the manuscript. MM, HD, and YM helped to analyze the data and revised the manuscript. HB supervised the clinical details and reviewed the final manuscript. All authors read and approved the final manuscript. 


\section{Ethics approval and consent to participate}

This report does not contain any directly identifiable patient details, and hence the need for ethics committee approval was waived.

\section{Consent for publication}

Written informed consent was obtained from the patient's legal guardian for publication of this case report and any accompanying images. A copy of the written consent is available for review by the Editor-in-Chief of this journal.

\section{Competing interests}

The authors declare that they have no competing interests.

\section{Publisher's Note}

Springer Nature remains neutral with regard to jurisdictional claims in published maps and institutional affiliations.

Received: 3 January 2018 Accepted: 6 June 2018

Published online: 13 July 2018

\section{References}

1. Kalkman CJ, Drummond JC, Kennelly NA, Patel PM, Partridge BL. Intraoperative monitoring of tibialis anterior muscle motor evoked responses to transcranial electrical stimulation during partial neuromuscular blockade. Anesth Analg. 1992;75:584-9.

2. Kawaguchi M, Inoue S, Kakimoto M, Kitaguchi K, Furuya H, Morimoto T, et al. The effect of sevoflurane on myogenic motor-evoked potentials induced by single and paired transcranial electrical stimulation of the motor cortex during nitrous oxide/ketamine/fentanyl anesthesia. J Neurosurg Anesthesiol. 1998;10:131-6.

3. Kalkman CJ, Drummond JC, Patel PM, Sano T, Chesnut RM. Effects of droperidol, pentobarbital, and ketamine on myogenic transcranial magnetic motor-evoked responses in humans. Neurosurgery. 1994;35:1066-71.

4. Minoshima R, Kosugi S, Nishimura D, Ihara N, Seki H, Yamada T, et al. Intra- and postoperative low-dose ketamine for adolescent idiopathic scoliosis surgery: a randomized controlled trial. Acta Anaesthesiol Scand. 2015;59:1260-8.

5. Gerbershagen HJ, Aduckathil S, van Wijck AJ, Peelen LM, Kalkman CJ, Meissner W. Pain intensity on the first day after surgery: a prospective cohort study comparing 179 surgical procedures. Anesthesiology. 2013;118:934-44.

6. Zaarour C, Engelhardt T, Strantzas S, Pehora C, Lewis S, Crawford MW. Effect of low-dose ketamine on voltage requirement for transcranial electrical motor evoked potentials in children. Spine (Phila Pa 1976). 2007;32:E627-30.

7. Ubags LH, Kalkman CJ, Been HD, Porsius M, Drummond JC. The use of ketamine or etomidate to supplement sufentanil/ $\mathrm{N}_{2} \mathrm{O}$ anesthesia does not disrupt monitoring of myogenic transcranial motor evoked responses. J Neurosurg Anesthesiol. 1997;9:228-33.

8. Scheufler KM, Zentner J. Total intravenous anesthesia for intraoperative monitoring of the motor pathways: an integral view combining clinical and experimental data. J Neurosurg. 2002:96:571-9.

9. Scheufler KM, Thees C, Nadstawek J, Zentner J. S(+)-ketamine attenuates myogenic motor-evoked potentials at or distal to the spinal alphamotoneuron. Anesth Analg. 2003;96:238-44.

10. Wang L, Johnston B, Kaushal A, Cheng D, Zhu F, Martin J. Ketamine added to morphine or hydromorphone patient-controlled analgesia for acute postoperative pain in adults: a systematic review and meta-analysis of randomized trials. Can J Anaesth. 2016:63:311-25.

\section{Ready to submit your research? Choose BMC and benefit from:}

- fast, convenient online submission

- thorough peer review by experienced researchers in your field

- rapid publication on acceptance

- support for research data, including large and complex data types

- gold Open Access which fosters wider collaboration and increased citations - maximum visibility for your research: over $100 \mathrm{M}$ website views per year 